\title{
A practice-based approach to design education
}

\author{
Bhagyashri Sharma ${ }^{1}$, Avik Roy ${ }^{2}$, Priyabrata Rautra ${ }^{3}$ \\ ${ }^{1}$ Pearl Academy \\ bhagyashri.sharma@pearlacademy.com \\ ${ }^{2}$ KIIT School of Architecture and Planning \\ avik.royfar@kiit.ac.in \\ ${ }^{3}$ IIT Hyderabad \\ md17resch11001@iith.ac.in
}

\begin{abstract}
In present times, the digital medium has made information accessible to everyone. This has resulted in design to be not limited by geographical, religious and cultural boundaries. Everyone across the world is experiencing the design and its impacts. According to the needs of the field of design, education has also modified itself. The methodology of teaching has gone through a drastic change. The pedagogical developments and its processes have also evolved accordingly. The field of design has always been more experimental in implementing various learning methodologies and is usually not limited by conventional methods like rote learning and bookbased instruction. Pedagogy for design has always been defined and regulated by the need of the industry and the interaction between professional practice and academics. Through this research, we have tried to understand various pedagogical taxonomies and methodologies such as Bloom and Kolb and how these are implemented and defined in accordance to the changing landscape of the industry. It also highlights the steps that students go through in a design process based on experiences, observations, conceptualisation and experimentation. It also charts the contemporary approaches which are undertaken primarily in the design education. Certain experimental studies were conducted in a design school to understand the pedagogical practices prevalent in the present day. The case studies revealed various types of learning methodologies such as visual, auditory and kinaesthetic. Another case study revealed that, though the students are digitally aware but experiential and hands-on learning still holds a lot of relevance and has been successful in holding the attention and interest of the student for a longer duration compared to digital media. In the second study, the students as a part of class activity conducted experiments by mapping the sunlight that enters the room through the various types of windows designed by them. While they were doing the experiments, the students were closely observed, and it showed that the engagement of the students and their overall learning that resulted was very high. Thus at the end of the experiment and the overall study, we could conclude that in
\end{abstract}


present times, the education should be balanced between digital and hands-on experiences. Ideation and conceptualisation of projects should be more experiential, rather than being on paper or in an intangible form. Design education should have equal content of digital visualisation and realisation in the form of model making and exploration.

\section{Keywords: design education, design learning, experimentation, pedagogy}

\section{Introduction}

Pedagogy is defined as "the science of teaching" (Bhowmik, M., Banerjee, B., \& Banerjee, J, 2013). That means pedagogy is a scientific process of applying techniques and decision making of the process and methodology of teaching. Sholle's definition is "all those practices that define what is important to know, how it is to be known, and how this production of knowledge helps to construct social identities" (Dutton, 1996). This is more comprehensive as it identifies pedagogy as a result of the social production of meaning. As Heraclitus said, "Change is the only constant"; thus, the pedagogical style keeps on changing. From the earlier times where there was only black-board teaching in design schools to the current time where more handson practices are applied. To understand more, let's look at the Bloom taxonomy (Bloom, B.S, 1956) which discusses the educational objectives. Bloom (Sprinthall \& Sprinthall, 1977; Wallschlaeger and Busic-Snyder, 1992) set three learning domains through the classification of educational goals, as shown in Figure 1.

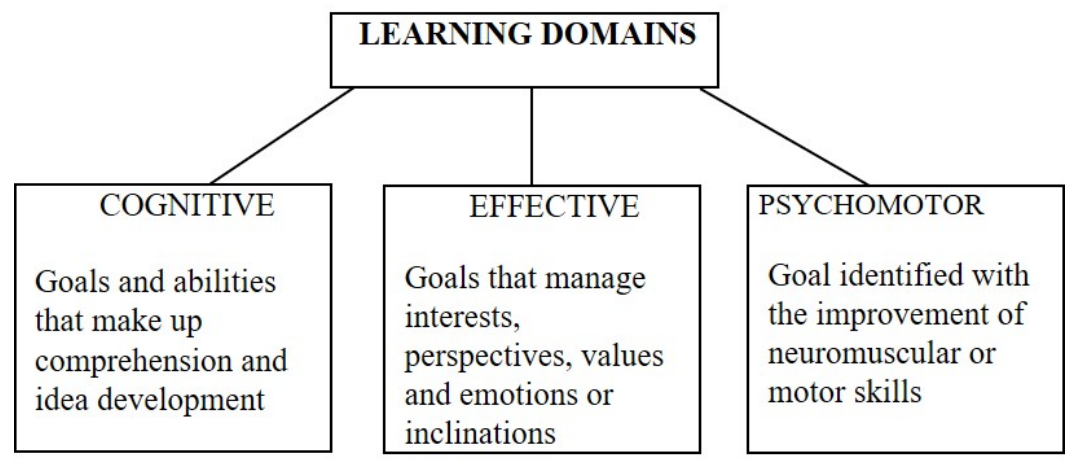

Figure 1. Taxonomy of educational objectives according to Bloom

This classification can be used in various domains and also in design education. According to it, selection should be made based on conceptual and mental skills, value additions and the hand skills (such as model making) that a student achieves through a course. According to Ledewitz (1985), there are three broad aspects of design academics (Farivarsadri, 2001)

a. Achieving new skills through representative and visual means

b. Design as a new language to express the ideas

c. Learning how to think creatively

The design students learn and also integrate these aspects into their design process. While learning these aspects, students face communication very challenging, especially in technical and theoretical topics. One of the issues is to teach the students all the necessary steps and skills through which they can present their ideas in less written, and more through graphical and verbal formats. According to Kolb (2007), knowledge is a creation of experiences and its transformation (Figure 2). Kolb explains that deep understanding of any topic can only happen 
when a student or learner goes through 4 primary stages based on experience, observation, concept development, and experimentation (Stice, 1987).

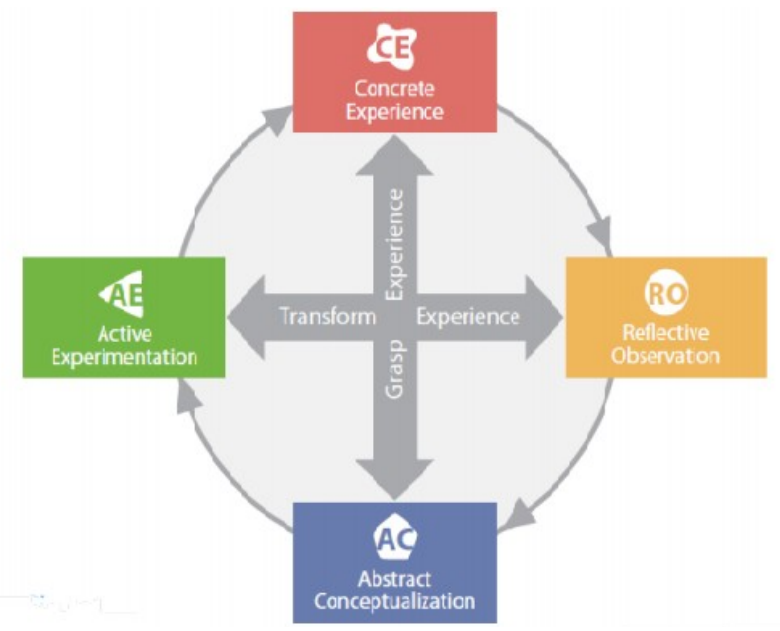

Figure 2. The Experiential Learning Cycle (Kolb, 2007:P9)

\section{Concrete experience:}

According to this, learning is through cognitive experience, and it doesn't happen just by observing or going through textual material. The individual needs to be involved and participate in the experience, just like swimming. A design student needs to experience the process such as carpentry before they can incorporate it in their designs (Demirbas \& Demirkan, 2007).

\section{Reflective observation:}

In the $2^{\text {nd }}$ stage, the student or the learner needs to reflect and review the experience so that they can generate an analysis. Through the analysis, they will be able to identify the issues in the scenario.

\section{Abstract conceptualisation:}

At this stage, based on the experience and its analysis, the students would generate their concepts which are probable or sketchy solutions to the identified issues. The concepts are expressed in form visualisations which helps for further analysis of the solution.

\section{Active experimentation:}

In this stage, the final design or the prototype is created after solving the identified issues. The prototype is then tested in real scenarios, so that's its further improvement can be done.

This research was done to understand the pedagogy of present-day design education and how it is different from the traditional direct instruction based teaching. Design subjects usually go through the experiential learning cycle, as discussed above. However, the technical and theoretical subjects become very monotonous because of the direct instruction based approach. In the case of theoretical subjects, students either have rote learning or documentation. In the case of technical subjects, students draft sheets to represent the detailings. In both cases, students have a very superficial learning experience, and they learn no methodology to implement the learning in realistic scenarios. 
It was hypothesised that if these subjects also traverse the same methodology of experiencing to experimentation, then the learning and engagement will be more profound. Case studies were adopted as the means of research methodology for this research. The case studies were also expected to highlight specific teaching methods that help in improving the learning experience of certain design subjects mainly in the technical topics for engaging students of the present generation. The case studies were conducted on two modules- anthropometry and technical drawings. The undergraduate students of interior design at Pearl Academy, Noida in India were part of the case study. The subjects and the syllabus remained constant, and the interventions were introduced at various stages of the module. And the engagement of the students was noted. The delivery of the module with new interventions discussed in detail with the faculties of the subjects. The following are the details as highlighted in the next two sections.

\section{Case study 1:}

The first case study was for Interior design module, which had 15 students. This was the first time when 'Anthropometrics' (anthro means human and metrics means measurement) was introduced to the students. This was the most crucial exercise for the batch as it forms the basis of their design education. The module is generally taught in a theoretical manner where students are expected to document. However, as a part of the experiment, the faculty tried to incorporate the following vital elements for deep learning in the class (Brown, 2007).

a) Motivational aspects

b) Classroom activity

c) Peer learning (Interaction with each other)

d) Well organised information

Learners needed to be highly engaged throughout the lecture to achieve all the elements mentioned above. Thus to keep the student motivated, learners were guided through a mix of various passive and active activities.

Few impromptu activities were also introduced to the learners in an otherwise theoretical subject as it improves the level of alertness among the students as well (Gholami \& Bagheri, 2013), during which it was ensured that peer learning is achieved. Group discussions, debates and quizzes were also conducted in the class to make the students proactive participants rather than being reactive observers.

Thus the instructions were more direct, pronouncing its outlines, limitations and methodologies. As per Biggs (2011), every learner has a different way of learning. VAK (Visual, Audio and Kinaesthetic) learning model was introduced in the class to make every learner engaged and involved (Gholami \& Bagheri, 2013). The type, of course, demanded that we choose a learning model which was well balanced between audio-visual or theoretical teaching with hands-on experience to generate comprehensive learning and VAK model was appropriate for that.

\section{Visual Learners}

These learners need the visual incitement of videos and films. They should be provided with directions so that class activities are conducted as expected (Oxford, 1995). GIF, images and videos were shown in the presentation to engage the students visually. (Figure. 3 shows an example of the presentation slides where correct anthropometrically and ergonomically body posture is shown). A few quizzes and puzzles were introduced to make the students more engaged. 


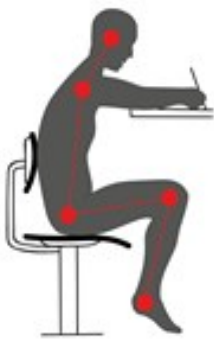

incorrect

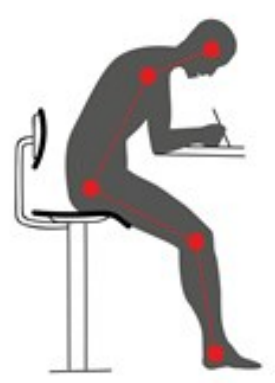

incorrect

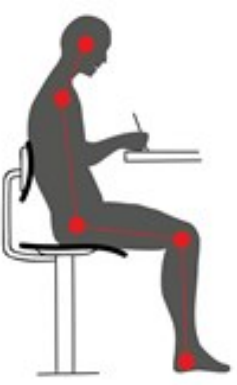

incorrect

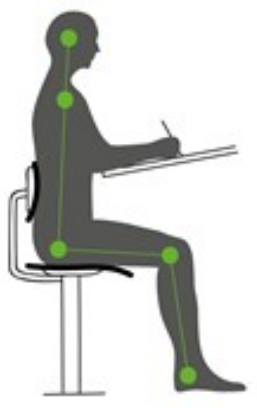

correct

Figure 3 Ergonomically and Anthropometrically correct sitting posture (Cameron, 2018)

\section{Audio Learners}

These learners are those who connect with verbal directions. They get engaged through discussions, oral quizzes, conversations etc. (Oxford, 1995). The class was very interactive, and students were engaged throughout the lecture. According to Sander, Stevenson, King, \& Coates (2000), students are more involved with interactive lectures as compared to formal lectures.

\section{Kinaesthetic learners}

These learners physically get involved in learning through experiences like role play, classroom activity, site visits etc. (Kinsella, 1995, p. 172). Experiential learning was introduced to the learner in the form of classroom activity, and they were asked first to form a pair and then measure each other. Once the measurements were done, they had to convert those measurements into scaled-down drawings. After finishing the task mentioned above, students were given various activities like cooking, bathing, making the bed, relaxing etc. to record the human postures. The students were asked to document the area required for performing these activities. This exercise benefited students in getting a deep understanding of space requirements and minimum dimensions as are necessary for each posture and movement (Figure 4 represent the mapping of bathing activity). For a better understanding of the width and height of three-dimensional space, they made wire models (Figure 4 describes the wire model of bathing activity).

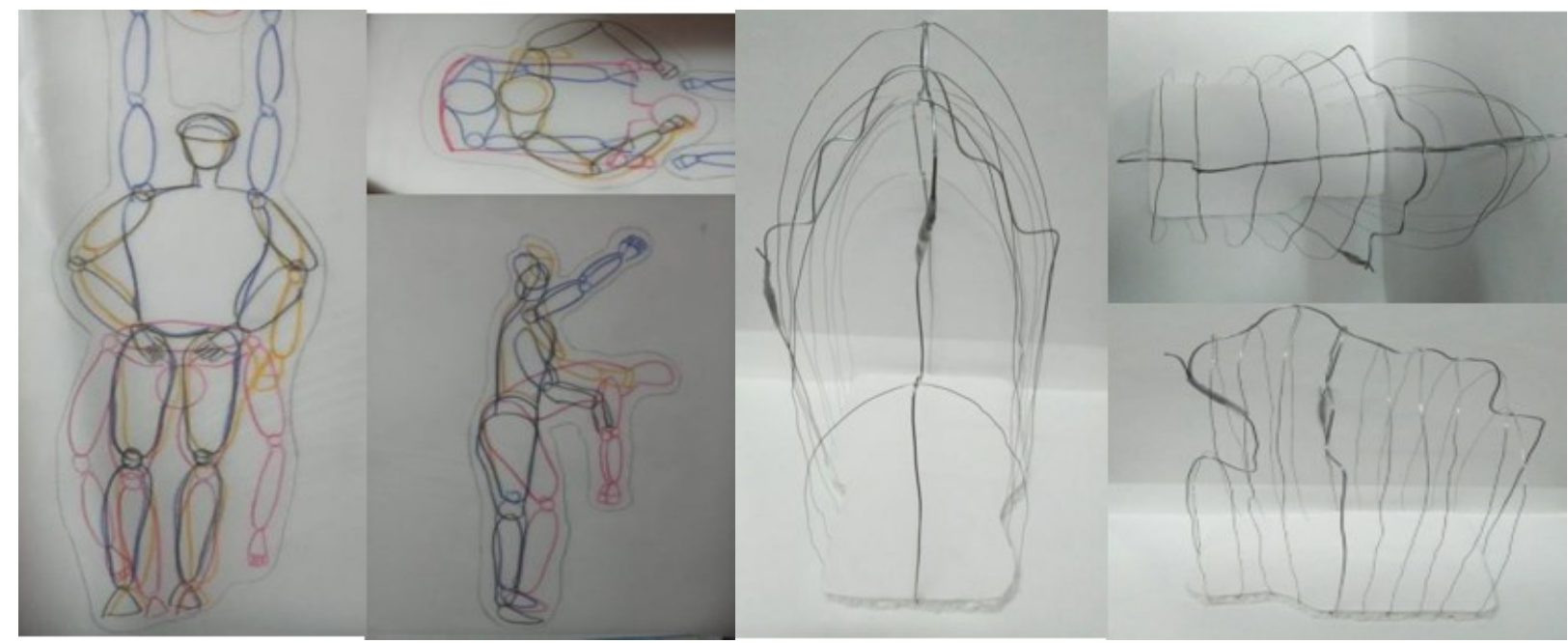

Figure 4. Bathing activity mapped and wire model, Photo Credit: Shivangi Singhal (Student)

Once they were able to achieve the understanding of space requirements and its interrelation with other spaces based on the activities, then they were asked to make the board model of 
various activities (as mentioned before) so that they can explore more options of zoning (Figure 6 ). With the help of this activity, students achieved the clarity on anthropometrics which will be useful while studying interior design and spatial relationship in future semesters.
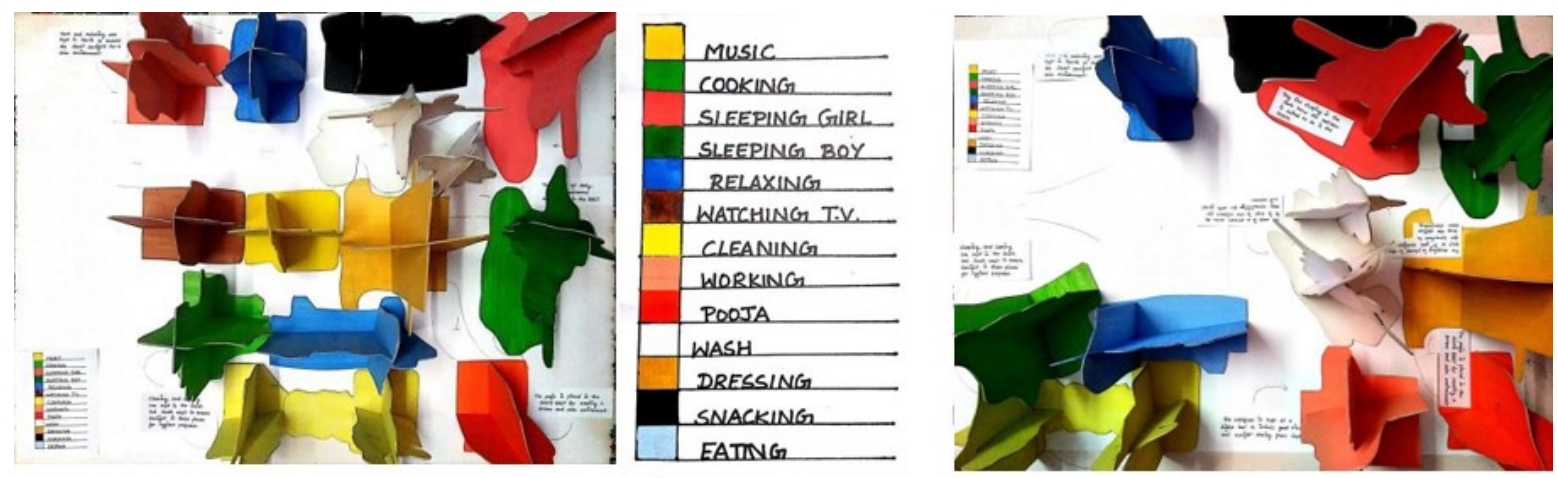

Figure 6. Massing exploration through various activity Anthropometric model Photo Credit: Shivangi Singhal (Student)

The pedagogical approach in this exercise ranged from theoretical, quizzes, videos, audios and activity-based, making it very comprehensive. The facilitator was able to achieve a high level of engagement by the students and create enthusiasm among them for the subject. The case study also revealed that a sudden introduction of activity resulted in increasing the alertness and the interest levels of the students. The multi-facet activities included in the course made the subject lively and broke the monotony.

\section{Case study 2:}

The second case study was based on the activity by one of the faculties of the school, Architect Nidhi Bindal as a part of the technical subject. Fifteen number of students were asked to design window systems that would achieve maximum daylight, minimum glare and maximum ventilation in indoor spaces. The faculty had planned the class activity for experiential learning. Though the students are usually not very excited about technical modules, through this exercise, the motive was to increase the interest and engagement of the student towards technical details. Students were asked to make four walls with different designs of windows, and they had to test how to achieve the requirements. They had to study the lighting through the windows in indoor space at three different times of the day from all the four directions (Figure 7). The students made scaled-down paper models and placed them in sunlight in a manner that light falls through these windows from one direction creating shade on the other side. The shadings were evaluated, and on assessing the quality of the shadows and the glare, the final window design was selected. The students converted the selected window designs into detailed drawings. 


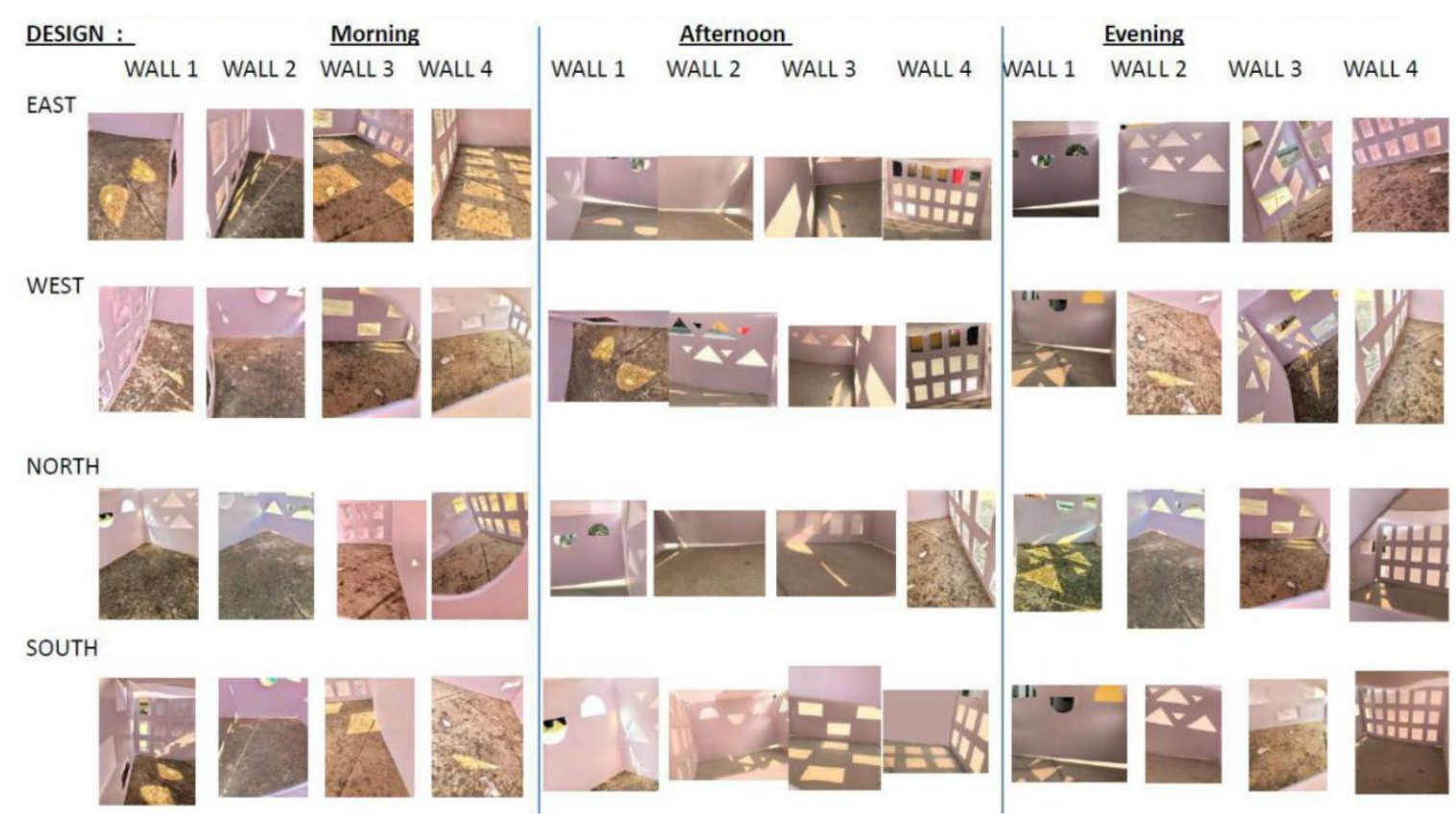

Figure 7. Students experimented on achieving the maximum daylight, minimum sunlight and maximum ventilation, Photo Credits: Rashi Bansal (Student)

The students were able to maintain their interest and engagement throughout the activity. The students were able to deduce the right dimensions of the windows and the placement of them to achieve better indoor daylighting, avoiding glare and optimising ventilation. It also taught them to explore their ideas from a concept level to a level of realistic understanding through experimentation. Based on this activity, they can in future design and place their window systems in more detail. Simulation through scaled models and the research process would help the students to explore, conceptualise and experiment during other aspects of their design as well. This activity also revealed that prototyping the ideas to create test models gives more concrete evidence of the feasibility of their design.

\section{Observation}

The case studies attempted to understand the approaches through experimentation in two different modules, anthropometry as a part of spatial design and technical drawings. In both cases, the strategy was to understand the requirements and explore the ideas and then experiment through test models. However, the representations of the results were different, considering the first module was more documentation and theory-oriented, and the second module was more technical detail-oriented. It was found that once the hands-on activity and experimentation is introduced, the understanding and clarity to achieve the desired representation became much clearer. If the students achieve complete clarity, they can interpolate their understanding of the required form of representation much more efficiently, whether through hand drawings or digital mode. It was also revealed that hands-on activities bring a more in-depth understanding and internalising of the fundamentals than attending lectures, researching on the internet or digital media.

In the case of the subject of anthropometry, the students understood how to measure and translate the measurements into proper technical drawings. The process was interspersed with quizzes, discussions, model making, sketching, and illustrations, making it a multi-layered 
approach. During the procedure, students learnt all the basic definitions and fundamentals. In the second case study, the students with the help of prototypes or test models of windows created a simulation. While creating the test models, they generated drawings, made paper models, studied the daylighting patterns, glare, shadows and mapped them as well. The identified the window systems which fulfilled the need of the assignment was then converted into technically detailed or working drawings. In this manner, the second case study also had a layered learning approach. Because of the layered approach of the topics, the students always had a self-driven task at a hand which maintained the engagement levels till the end.

With the above case studies, it can be derived that specifically for theoretical and technical aspects of design education, that these should be approached experientially than limiting them to classroom lecture-based exercises. Once the student can experiment with the concepts, they will be able to apply it more aptly. The learning, in this case, would be more profound. The engagement of the students would also be high compared to attending lectures.

Thus, based on these case studies, the intended learning outcomes (Biggs \& Tang, 2007) were formulated, and reviewed based on verbal feedback of students as mentioned below (Table 1):

Table 1: Alignment between Intended Learning Outcomes and Teaching/Learning Activities

\begin{tabular}{|c|c|c|c|c|}
\hline SI No & $\begin{array}{l}\text { Intended } \\
\text { Learning } \\
\text { Outcomes }\end{array}$ & Action Verb & Content & $\begin{array}{l}\text { Students Feedback } \\
\text { on Intended } \\
\text { Learning Outcome } \\
\text { achieved }\end{array}$ \\
\hline \multirow[b]{2}{*}{1} & \multirow{2}{*}{$\begin{array}{l}\text { LO 1- Observe, } \\
\text { the document, and } \\
\text { apply } \\
\text { aspects through a) } \\
\text { Case study 1- the } \\
\text { human body in the } \\
\text { design of } \\
\text { spaces and objects. } \\
\text { b) Case study 2- } \\
\text { Daylighting of } \\
\text { internal spaces }\end{array}$} & \multirow{2}{*}{$\begin{array}{l}\text { Document, } \\
\text { Observe } \\
\text { and apply }\end{array}$} & $\begin{array}{l}\text { Case Study 1-Aspects of } \\
\text { the human body in the } \\
\text { design of } \\
\text { spaces and objects }\end{array}$ & $80 \%$ \\
\hline & & & $\begin{array}{l}\text { Case Study 2- } \\
\text { a) Understanding the } \\
\text { Principles } \\
\text { b) Understanding of } \\
\text { construction techniques }\end{array}$ & $\begin{array}{l}\text { a) } 80 \% \\
\text { b) } 50 \%\end{array}$ \\
\hline \multirow{2}{*}{2} & \multirow{2}{*}{$\begin{array}{l}\text { LO 2- Integrate and } \\
\text { apply basic } \\
\text { volumetric, } \\
\text { functional, } \\
\text { and aesthetic } \\
\text { principles such as } \\
\text { material to the } \\
\text { design of an } \\
\text { individual } \\
\text { space }\end{array}$} & \multirow{2}{*}{$\begin{array}{l}\text { Apply and } \\
\text { Integrate }\end{array}$} & $\begin{array}{l}\text { Case Study 1- } \\
\text { a) Volumetric, functional } \\
\text { b) aesthetic principles to } \\
\text { the design of an individual } \\
\text { space }\end{array}$ & $\begin{array}{l}\text { a) } 90 \% \\
\text { b) } 90 \%\end{array}$ \\
\hline & & & $\begin{array}{l}\text { Case Study 2- } \\
\text { Examine and evaluate } \\
\text { building functioning } \\
\text { concerning daylighting }\end{array}$ & $60 \%$ \\
\hline \multirow{2}{*}{3} & \multirow{2}{*}{$\begin{array}{l}\text { LO 3- Respond to } \\
\text { simple design briefs } \\
\text { with self-critique, } \\
\text { reflection and } \\
\text { Discussion with } \\
\text { peers. }\end{array}$} & \multirow{2}{*}{ Reflection } & $\begin{array}{l}\text { Case Study 1- Design } \\
\text { brief, Self-critique } \\
\text { discussion with peers }\end{array}$ & $75 \%$ \\
\hline & & & $\begin{array}{l}\text { Case Study 2- Design } \\
\text { brief, self-critique } \\
\text { discussion with peers }\end{array}$ & $80 \%$ \\
\hline
\end{tabular}




\begin{tabular}{|c|c|c|c|c|}
\hline \multirow[t]{2}{*}{4} & \multirow{2}{*}{$\begin{array}{l}\text { LO 4- Create basic } \\
\text { abstract } \\
\text { diagrams, concepts } \\
\text { sketches, and models } \\
\text { as tools to generate } \\
\text { progressive design } \\
\text { options. }\end{array}$} & \multirow[t]{2}{*}{$\begin{array}{l}\text { Create and } \\
\text { generate }\end{array}$} & $\begin{array}{l}\text { Case Study } 1 \text {-Abstract } \\
\text { diagrams, } \\
\text { sketches, and models } \\
\text { as tools for } \\
\text { progressive design } \\
\text { options. }\end{array}$ & $90 \%$ \\
\hline & & & $\begin{array}{l}\text { Case Study 2- } \\
\text { a) Concept to design } \\
\text { b) Useable design output } \\
\text { c)Functionality }\end{array}$ & $\begin{array}{l}\text { a) } 100 \% \\
\text { b) } 100 \% \\
\text { c) } 60 \%\end{array}$ \\
\hline
\end{tabular}

\section{Conclusion}

The design has become a bridge between the aspirations of people and functionality. The journey of design needs to start from visualisation and end at the physical realisation of the idea. However, to incorporate optimum functionality, the designers at their academic level itself should be armed and taught with the right tools of researching. In design education, there are various subjects which are theoretical and technical and highly relevant in the overall development of a designer. To impart in-depth knowledge to students, more and more design schools are incorporating more experiential and hands-on activities. The process of learning should be sincere and not superficial (Samarakoon, Fernando, Rodrigo \& Rajapakse, 2013), and this study has tried to explore the methods that generate deep learning.

Based on the above case studies, followings were the insights:

1. Hands-on exercises help the student to understand the concept better. So we can conclude that experiential learning in design schools should be encouraged.

2. It's essential to update with the new methodologies and introduce more digital media. Still, it should be balanced with hands-on activity so that they develop a more robust understanding of the fundamentals. The approach should be contemporary towards the aspirations of the present generation.

3. Prototyping the ideas and detailings helps students to internalise technical data better.

4. The experiment concluded that they should be introduced to a concept in a manner which can later be used in a realistic scenario in future.

Thus it's essential for the faculty to also reflect on what they have taught, how the learner has perceived it, and what the outcome is. Thus a constant never-ending progression can be seen in the student's result and faculty's development.

\section{References}

Bhowmik, M., Banerjee, B., \& Banerjee, J. (2013). Role of pedagogy in effective teaching. Basic Research Journal of Education Research and Review, 2(1), 1-5.

Biggs, J. B. (2011). Teaching for quality learning at university: What the student does. McGraw-hill education (UK).

Biggs, J., \& Tang, C. (2007). Teaching for quality learning at university. Maidenhead. Berkshire, UK: McGraw-Hill Education. 
Bloom, B. S. (1956). Taxonomy of educational objectives. Vol. 1: Cognitive domain. New York: McKay, 20-24.

Brown, G. (2004). How Students Learn: A supplement to the RoutledgeFalmer Key Guides for Effective Teaching in Higher Education series. The Medical Teacher, 24, 1-50.

Cameron, S. (2018, April 24). Six Tips to Help Save Yourself from Poor Computer Posture. Retrieved from How-To Geek: https://www.howtogeek.com/349796/six-tips-to-helpsave-yourself-from-poor-computer-posture/

Dutton, T. A. (1996). Cultural studies and critical pedagogy: Cultural pedagogy and architecture. Reconstructing Architecture: Critical Discourses and Social Practices, University of Minnesota Press, Minneapolis, Minnesota, USA, 158-201.

Demirbas, O. O., \& Demirkan, H. (2007). Learning styles of design students and the relationship of academic performance and gender in design education. Learning and instruction, 17(3), 345-359.

Farivarsadri, G. (2001). A Critical view on pedagogical dimension of introductory design in architectural education. Architectural Education Exchange, 2001, 11-12

Gholami, S., \& Bagheri, M. S. (2013, July). Relationship between VAK Learning Styles and Problem Solving Styles regarding Gender and. Journal of Language Teaching and Research, pp. 700-706.

Kolb, A. Y. (2013). The Kolb Learning Style Inventory 4.0: A comprehensive guide to the theory, psychometrics, research on validity and educational applications. Philadelphia, PA: Hay Group.

Ledewitz, S. (1985). Models of design in studio teaching. Journal of Architectural Education, pp 2-8.

Reid, J. M. (1995). Learning styles in the ESL/EFL classroom. Heinle \& Heinle Publishers, International Thomson Publishing Book Distribution Center, 7625 Empire Drive, Florence, KY 41042

Samarakoon, L., Fernando, T., Rodrigo, C., \& Rajapakse, S. (2013). Learning styles and approaches to learning among medical undergraduates and postgraduates. BMC medical education, 13(1), 42 .

Sander, P., Stevenson, K., King, M., \& Coates, D. (2000). University students' expectations of teaching. Studies in Higher education, 25(3), 309-323.

Sprinthall, R. and Sprinthall, N. A. (1977), Educational Psychology: A Developmental Approach, Reading MA: Addison-Wesley

Stice, J. E. (1987). Using Kolb's Learning Cycle to Improve Student Learning. Engineering education, 77(5), 291-96. 